students at PSU and support the picture of PSU female undergraduates showing greater spread on all variables, higher mean performance on verbal ability tests and high school grades and lower mean performance on mathematical aptitude measures.

RESULTS AND DISCUSSION

The results of the correlational analyses of $m$ and ability and achievement measures are summarized in Table 2 . Two findings seem at once apparent; there are a few significant, but modest, relationships between $m$ and indicants of verbal skills (vocabulary, punctuation, and total scores on English placement test), and these relationships hold for male Ss only. For females there are no significant correlates of $m$ among any of the achievement and ability variables studied, despite the females' consistently greater spread of scores on such measures and, hence, a concomitantly better opportunity for detection of correlates. A subsidiary finding of significantly $(p<.01)$ greater $m$ mean for females $(10.4 \pm 2.2$ vs $9.3 \pm 2.3$ for males) supports a similar finding reported by Matthews (1965).

Hypotheses regarding the differential relatedness in males and females of $m$ and the variables studied here can be tentatively entertained but seem within the realm of the extremely speculative considering the magnitude of the relatedness difference (none vs slight). With these reservations in mind, the data might be considered congruent with accumulating evidence regarding sex differences in cognitive style (Witkin, Lewis, Hertzman, Machover, Meissner, \& Wapner, 1954). Thus, the present results may partly reflect the greater field orientation (and hence stimulus dependence) of females, although such an interpretation obviously calls for more direct support.

Summarizing the results of this investigation, it appears that within a college population none (for females) or very little (for males) of the intersubject variance in associative response availability can be accounted for in terms of intellectual ability and achievement variables. Barring subsequent evidence to the contrary, the pragmatic value of these data may lie in the suggestion that it is appropriate to continue disregarding ability and achievement variables in exploring sources of individual differences in $m$ in a college population.

\section{REIERENCES}

BOUSEFIELD, W. A.. \& SAMBORSKI, G. The relationship between strength of values and the meaningfulness of value words. Journal of Personality. 1955, 23. 375-380.

CRAMIE. P. W'ord association. New York: Academic Press, 1968.

DAVIDS. A.. \& ERIKSON. C. W. The relation of manifest anxiety to association productivity and intellectual at tainment. Journal of Consulting Psychology, 1955 . 19, 219-222.

DIERING. G. Affective stimuli and disturbance of

Table 2

Relationships Between $m$ and Various Ability and Achievement Measures in a College Population

\begin{tabular}{lcc}
\hline Measure & Males & Females \\
\hline SAT Verbal & .10 & .14 \\
SAT Math & -.01 & .04 \\
SAT Total & .06 & .11 \\
English: Spelling & .17 & .01 \\
English: Vocabulary & $.24^{*}$ & .03 \\
English: Punctuation & $.23^{*}$ & -.05 \\
English: Grammar & .08 & -.04 \\
English: Total & $.26^{*}$ & -.01 \\
Reading Comprehension & .09 & -.01 \\
Chemistry & .05 & .07 \\
High School Average & .04 & .03 \\
Predicted GPA, Non Science & .09 & .10 \\
Predicted GPA, Science & .06 & .08 \\
Cumulative GPA & .08 & .02 \\
\hline
\end{tabular}

${ }^{*} p<.05$

thought processes. Journal of Consulting Psychology, 1963, 27, 338-343.

JOHNSON, R. C., \& LIM, D. Personality variables in associative production. Journal of General Psychology, 1964, 71, 349-350.

LAFFAL, J. Response faults in word association as a function of response entropy. Journal of Abnormal \& Social Psychology, 1955, 50, 265-270.

LESTER, J. R. Production of associative sequences in schizophrenic and chronic brain syndrome. Journal of Abnormal \& Social Psychology, 1960,60, 225-233.

MATTHEWS, W. A. The relation between association norms and word frequency. British Journal of Psychology, 1965, 56, 391-399.

MEDNICK, M. T., MEDNICK, S. A., \& JUNG, C. C. Continual association as a function of level of creativity and type of verbal stimulus. Journal of Abnormal \& Social Psychology, 1964, 69, 511-515.
NOBLE, C. E. An analysis of meaning. Psychological Review, 1952,59,421-430.

SHAPIRO, S. S. Word associations and meaningfulness values for grade-school-aged children. Psychological Reports, 1964, 15, 447-455.

VAN KREVELEN, A. Relationships between number of verbal associations to value words and subjective ratings of value. Proceedings of the Iowa Academy of Science, 1956, 63, 576-580.

WITKIN, H. A., LEWIS, H. B., HERTZMAN, M., MACHOVER, K., MEISSNER, P. B., \& WAPNER, S. Personality through perception. New York: Harper \& Row, 1954. NOTE

1. This project was supported by the Central Fund for Research of the Pennsylvania State University. Appreciation is expressed to Dr. Carl A. Lindsay of the Office of Student Affairs Research, The Pennsylvania State University, for making available the achievement and ability data.

\title{
Retroactive inhibition and extended recall time'
}

\author{
JOHN P. HOUSTON, University of Califor- \\ nia, Los Angeles, Calif. 90024
}

Subjects learned a single $A-B$ or successive $A \cdot B, A-C$ lists and were then tested for recall of the first-list materials after 1 week. In the MIMFR conditions a typical MMFR task was administered. In the extended conditions $S s$ were allowed I week to try to recall the materials. Both recall techniques produced significant RI. Ss in the extended conditions were able to recall a significant number of additional items during the week provided for recall. In agreement with the contention that competition has little effect upon recall, and in contrast to the assumption that extended recall might allow for the dissipation of competition effects, equal amounts of RI were obtained with the two recall techniques. 
The two-factor theory of forgetting (Melton \& von Lackum, 1941) states that more retroactive inhibition (RI) should be obtained with paced than unpaced recall procedures. Competition at the time of recall is presumed to operate when the $S$ is limited in terms of the amount of time he is allowed for recall of each first-list item. The assumption has been that competition will produce a decrement in first-list recall if the conventional 2-sec paced recall procedure is employed but will not if the modified, modified free recall (MMFR) technique is used. Contrary to expectations, comparisons of 2-sec paced and MMFR procedures have not produced unequivocal support for the competition hypothesis. Few, if any, differences in absolute RI have been obtained with the two procedures. Although differences have been obtained when $R \mathbf{I}$ was measured in percentages, Houston (1968) argues that these comparisons may be inappropriate because the percentage or relative measures artificially favor a greater loss in the paced conditions.

Houston (1968) felt that the failure to find a clear-cut difference between paced and MMFR conditions might have been due to the fact that the paced procedures did not put enough time pressure on the $S$. That is, the 2-sec procedure might allow too much time for competition effects to appear. Accordingly, he increased the time pressure by employing MMFR, 2-sec, 1.5-sec, 1-sec, and .5 -sec recall times. Again differences in absolute RI did not appear among the conditions.

Another logical explanation for the failure to find significant absolute differences is that the MMFR task may not allow enough time for competition effects to be eliminated. Although MMFR recall times are almost never reported in the literature, it appears that the MMFR method seldom involves more than $1 \mathrm{~min}$ for the recall of each item. This may not be enough time for the elimination of competition effects. Accordingly, Ss in this study learned two successive paired-associate lists and were then, after a l-week retention interval, tested for first-list recall with a typical MMFR task or were allowed up to 1 week to attempt recall of the materials. If the hypothesis is correct and the typical MMFR task does not allow enough time for the dissipation of competition effects, then one would expect greater RI to be obtained with MMFR than with 1-week extended recall.

\section{METHOD}

The experiment involved a 2 by 2 design All Ss first learned an A-B list to a criterion of one perfect trial. Half the Ss then learned an A-C list for 15 anticipation trials. The remaining factor referred to the type of recall test administered (MMFR or extended). The Ss were 48 undergraduates.
Participation partially fulfilled a psychology course requirement. The four conditions were arranged in 12 blocks such that each condition occurred once in each block. The Ss were assigned to this arrangement as they appeared in the laboratory.

The CVC-adjective lists were the A-B, A-C materials used and described by Barnes $\&$ Underwood (1959). One set was always used as the A-B list and the other as the A-C list. Two different pairings of the stimulus and response materials were used equally frequently. Three unsystematic presentation orders were developed and each was used equally frequently as the starting order. All learning was at a $2: 2-\sec$ presentation rate on aStowe drum. Four-second intertrial and $60-\mathrm{sec}$ interlist intervals were employed. Upon returning to the laboratory after 1 week MMFR Ss were given a walle t-size card containing the stimuli in a new random order. Experimental Ss were instructed to record both first- and second-list responses next to the correct stimuli in the spaces provided. Control Ss were asked to record the responses from the single list they had learned. The Ss were informed that they had as much time as they wished and that the order of recall was not important. Extended Ss were treated in exactly the same manner except that, when they indicated that they were finished, they were asked to take the card with them for 1 week. They were to record any additional responses they remembered during the week. They were told that their recall might be aided if they occasionally looked at the stimulus units during the week. Extended Ss returned their cards to the laboratory after 1 week.

RESULTS AND DISCUSSION

The mean numbers of trials required by the control-MMFR, experimental-MMFR, controlextended, and experimentalextended groups to reach first-list criterion were $8.75,8.00,7.33$, and 6.41 , respectively. These means did not differ significantly (Fs $<1.18$ ). The mean numbers of correct second-list responses produced by the experimental-MMFR and experimentalextended groups were 83.66 and 87.66 , respectively. These means did not differ significantly $(t<1)$.

The mean numbers of first-list responses recalled correctly by the control-MMFR, experimental-MMFR, control-extended and experimental-extended groups were $4.17,3.25,5.08$, and 3.25 , respectively. The control conditions produced significantly better recall than the experimental conditions $[F(1,44)=5.29, p<.05]$, indicating that a significant RI effect appeared in the experiment. Although extended recall produced somewhat better recall than the MMFR method, the difference was not significant $(F<1)$. The most important finding was that the interaction was not significant $(F<1)$. This was in contrast to the prediction that an increase in recall time would allow for the dissipation of competition effects and a corresponding decrease in the RI phenomenon. Both relative and absolute $\mathrm{RI}$ appear, if any thing, to be greater in the extended condition. This result lends some support of Houston's (1968) contention that the effects of time-dependent competition upon recall are quite limited.

When the extended Ss were given their recall cards, they were subjected to an MMFR test before they left the laboratory. That is, they attempted to write down as many of the correct responses as they could before they left. These responses were recorded by $E$. Thus it was possible to compare MMFR and extended recall for the same Ss. When the data were broken down in this way, with the same Ss serving in both the MMFR and extended conditions, the mean recall values for the control-MMFR, experimental-MMFR, control-extended, and experimental-extended conditions were $4.58,2.42,5.08$, and 3.25 , respectively. A repeated measures analysis of variance again indicated a significant RI effect $[F(1,22)=5.67, p<.05]$. In this case extended recall was significantly better than initial MMFR performance. That is, Ss appeared to be able to recall a significant number of additional items during the week-long retention interval. Again the interaction was not significant $(F<1)$. Thus both analyses suggest that RI did appear but that the amounts of absolute RI obtained in the MMFR and extended conditions did not differ. One might want to argue that, in the repeated measures analysis, relative $R I$ appeared to be greater in the MMFR than in the extended condition. But this bit of information is all that could be used to support the notion that increasing recall time decreases $\mathrm{RI}$. The most reasonable conclusion would seem to be that the experiment offers little support for the competition hypothesis. Houston (1968) has suggested that the phenomena which have been traditionally interpreted in terms of competition (e.g., proactive inhibition) might better be understood in terms of undetected rehearsal and unlearning which may occur during the retention interval.

\section{REFERENCES}

BARNES, J. M., \& UNDER WOOD, B. J. "late" of first-list associations in transfer theory. Journal of Experimental Psychology, 1959, 58,97-105.

HOUSTON, J. P. Competition in the two-factor theory of forgetting. Journal of Verbal Learning \& Verbal Behavior, 1968, 7, 496-500.

MELTON, A. W., \& von LACKUM, W. J. Retroactive and proactive inhibition in retention: Evidence for a two-factor theory of retroactive inhibition. American Journal of Psychology, 1941, 54, 157-173.

$$
\text { NOTE }
$$

1. This work was supported by USPHS Grant No. MH 15336-01. 